\title{
EYE: a journal to be proud of
}

Eye (2013) 27, 575-576; doi:10.1038/eye.2013.49

Eye is the official journal of the Royal College of Ophthalmologists. It aims to provide the practising ophthalmologist with information on the latest clinical and laboratory-based research. Eye has evolved over the 25 years of the College of Ophthalmologists' existence. Peter Watson, the first editor-in-chief, describes some of its history below.

EYE began its history in 1985 at the council meeting of the Ophthalmological Societies of the United Kingdom (OSUK) in the large committee room of the Royal Society of Medicine when Professor Ashton formally proposed the formation of the Royal College of Ophthalmologists.

The OSUK's journal was the Transactions of the Ophthalmological Societies of the United Kingdom, which was one of the oldest of the world's ophthalmic journals established by Sir William Bowman in 1881. Its purpose was to record the discussions of the various societies throughout the UK, so disseminating up-to-date

information on eye disease throughout the land. This it did successfully right though until 1986, when, as its title was no longer appropriate with the formation of the new college, the then editor, Patrick Trevor-Roper, changed the title to EYE. Volume 1 of the new journal appeared in 1987.

Peter Watson became editor in the next year. For several years previously the Transactions OSUK had been open to those wishing to publish articles on topics that had not been presented at one of the meetings, but this rarely happened. To be certain of a high standard of articles in the new journal, steps were taken to ensure that all the named lectures of the various societies were published in EYE together with a selection of the best papers from the main meetings. As a consequence, excellent unsolicited articles were soon being submitted and the citation rate rose rapidly.

The Cambridge Ophthalmological Symposium had occupied one issue of the Transactions OSUK since 1974. (Two of the previous three symposia had appeared as

AJ Lotery and P Watson

supplements to the $B J O$ and the other as a book on 'Corneal Graft Failure' in the CIBA symposium series.) As all those who contribute to the Cambridge Symposium are required to submit their paper for publication, this has ensured that everyone has access to an up-to-date, comprehensive summary of the science and clinical applications of the topic discussed in the previous year. For this reason the Cambridge Symposium continues to publish its transactions in full in EYE.'

Ian Rennie was the second editor of Eye and successfully negotiated its transition from a paper-based journal, run from a filing cabinet in his office, (!) to an online journal with an electronic workflow managed by Nature Publishing Group. The third and current editor-in-chief is Andrew Lotery. During his tenure, submissions continue to increase, with approximately 100 manuscripts being submitted per month for consideration for publication. Consistent with other leading journals, only the best papers are accepted with a current acceptance rate of $25 \%$. However, despite the increased number of submissions, the time to review decisions being made has progressively decreased. Currently the median time to first decision is 39 days and the average time to online (and citable) publication is 27 days. This is due to the tireless work of the international editorial board and the reviewers.

Moving with the times, Eye now publishes podcasts, provides electronic continuing professional development, and receives over 2 million page views per year online. In an associated web focus to this editorial, see www.nature.com/eye/focus/anniversary/ index.html, the three editor-in-chiefs of Eye have highlighted 15 of the best papers published in Eye over the last 25 years. I encourage you to go online and review them. They include some of the seminal first descriptions of limbal stem cells, the pathophysiology of macular degeneration, diabetic retinopathy, and ischaemic optic neuropathy, as well as ground-breaking clinical papers on topics such as trabeculectomies and
Southampton Eye Unit, University of Southampton, Southampton General Hospital, Southampton, UK.

Correspondence: AJ Lotery, Southampton Eye Unit, University of Southampton, Southampton General Hospital, Southampton, UK. Tel: +44 (0)23 8089 4590; Fax: +44 (0)23 80794120 . E-mail: a.j.lotery@soton. ac.uk 
pharmacogenomics. They also highlight the power of the NHS to achieve worthwhile clinical studies with data sets of over 55000 patients. We congratulate the College on its 25th anniversary. Looking forward, Eye will continue, like the Royal College of Ophthalmologists, to innovate with the times. Its focus will continue to be aimed at publishing the best clinical and laboratorybased research. Consequently, we hope members of the Royal College of Ophthalmology will feel justly proud of their journal. 